Статья с открытым доступом под лицензией CC BY-NC-ND (https://creativecommons.org/licenses/by-nc-nd/3.0/) Материалы Международной практической интернет-конференции «Актуальные проблемы науки»

Выпуск II, ноябрь 2019

ISBN 978-601-323-144-0

https://doi.org/10.31643/2019.013

Муканова Динара Базаровна

«Республиканский научно-исследовательский институт по охране труда Министерства труда и социальной защиты населения» РГП на ПХВ

Старший научный сотрудник лаборатоии иссследования условий труда

Магистр экономических наук, г.Нур-Султан, Казахстан E-mail: nauka@ rniiot.kz

ORCID ID: 0000-0002-1744-6151

\title{
Обзор источников по вопросу разработки и внедрения системы управления охраной труда
}

\begin{abstract}
Абстракт: В статье приведен анализ подхов по внедрению системы управления охраной труда на основе анализа различных авторов. Авторы анализированных работ предлагают внедрение разделить на два, три или четыре этапа, но в одном мнение авторов совпадает. Весь процесс внедрения необходимо разделить на последовательные этапы. Наличие единой модели системы управления охраной труда позволяет устанавливать соответствие действий работодателя по охране труда нормативным требованиям охраны труда и безопасности производства. Процесс внедрения на предприятиях СУОТ должен быть систематизирован и поделен на несколько этапов, каждый из которых должен иметь свои задачи. Это подтверждается опытом внедрение системы управления охраной труда, апробированным международной практикой и вполне успешно применяется предприятиями на практике.
\end{abstract}

Ключевые слова: внедрение, алгоритм, этапы, система управления охраной труда, безопасность.

Анализ литературных источников показал, что наиболее эффективно управлять охраной труда возможно только при использовании системного подхода. Идеология управления охраной труда предусматривает комплексный подход к формированию и реализации политики в области охраны труда, при которой все элементы взаимосвязаны и работают в четком взаимодействии.

Результаты анализа нормативных правовых документов и научной литературы свидетельствуют о том, что система управления безопасностью и охраной труда в странах бывшего Советского союза начала развиваться в 80-х годах прошлого столетия. Созданию системы управления охраной труда (далее- СУОТ) предшествовали многие законодательные и нормативные документы, подготавливая условия для создания системности в работе по охране труда.

На основе законодательных и нормативных документов впервые, в 1986 году были разработаны «Рекомендации по внедрению системы управления охраной труда в колхозах, совхозах и других сельскохозяйственных предприятиях». По мнению авторов Пушилина Н.К и Трубицина Н.В., разработанные рекомендации не имели перечень элементов системы, и внедрять ее было очень тяжело из-за недостаточного понимания самой системы управления охраной труда [1].

В связи с этим, в 1987 году были разработаны «Общие положения и методические указания по управлению охраной труда в системе Госагропрома СССР» [2]. Этот документ оказался более конкретным и целенаправленным, его можно было применить к непосредственной работе по созданию СУОТ в организациях. Указанный нормативный документ был взят за основу при разработке Межгосударственного стандарта ГОСТ 1.0.230 - 2007 [3].

Ученые А. Ахметов и У. Ибатуллин в своих работах предлагают различные алгоритмы подготовки и внедрения системы управления охраной труда на предприятии [4]. 
Весь алгоритм внедрения СУОТ они разделили в два последовательных этапа:

- опытная апробация системы, где проводится корректировка разработанной документации и проверка функционирования отдельных элементов системы на практике.

- окончательное введение СУОТ в действие.

Для перехода к новой системе управления охраной труда А. Ахметов и У. Ибатуллин выделили три необходимых условия:

- вместо фактического реагирования на происшествия и материальной компенсации неблагоприятных последствий использовать систему оценки и управления профессиональными рисками;

- произвести замену системы формальных наказаний за несоответствие требованиям действующего законодательства на систему экономического стимулирования обеспечения безопасных условий труда;

- внедрение безопасных технологий и использование в системе страхования индивидуальные тарифы, рассчитанные по фактическим показателям профессионального риска.

Предложенный учеными алгоритм подготовки и внедрения системы управления охраной труда на предприятии включает три основных этапа: предварительный, подготовительный и основной. На предварительном этапе принимается решение о разработке и внедрении СУОТ, а также издается соответствующий приказ. На подготовительном этапе главная задача состоит оценке текущего состояния условий труда, качественной и количественной оценке эффективности, действующей СУОТ. Основной этап внедрения включает: разработку Политики и цели в области безопасности и охраны труда, Плана внедрения, методического обеспечения, а также реализацию функционирования СУОТ. Данный алгоритм и процедуры заслуживают внимания, учитывая целенаправленность каждого этапа и их взаимосвязь в общем процессе внедрения.

Е. В. Юркинская, как и вышеназванные авторы, делит процесс внедрения СУОТ на предприятии на три этапа [5]:

$>$ предварительный этап (решение руководства о создании системы, проведение предварительной оценки системы);

$>$ внедрение (разработки политики, разработка целей и задач, планирование работ, выделение и описание процессов, обучение персонала, создание и поддержание системы мониторинга и осуществление корректирующих мероприятий на его основе);

$>$ подготовка системы к сертификации (разработка методических основ проведения сертификационного аудита системы менеджмента качества и системы управления окружающей средой в процессе сертификации на основе требований МС ИСО 19011).

Для внедрения СУОТ Ю. В. Дмитриева, в своей научной работе предлагает также, деление процесса внедрения на три этапа: предварительной оценки, планирования и самого внедрения [6]. Автор считает, что предварительная оценка состояния охраны труда должна стать опорной точкой для измерения степени развития системы. На этапе планирования определяется цель создания такой системы, которая: как минимум, обеспечит соблюдение требований законодательства по охране труда; включит в себя необходимые элементы СУОТ и обеспечит постоянный рост эффективности охраны труда.

А. А. Кулешов и Н. Г. Николаева предлагают весь процесс внедрения СУОТ на предприятии разделить на 4 этапа [7].

Первый этап - диагностика и анализ системы. Он включает в себя сбор данных, анализ данных, оценку величины риска, анализ последствий, документальное обоснование. На данном этапе проводится оценка риска. Разрабатываются методики идентификации опасностей и рисков на рабочих местах, а также определяются меры по предотвращению или снижению их уровня (это состав второго - подготовительного этапа, описанный в работах предыдущих авторов).

Второй этап - планирование, где определяется политика, цели и задачи в области охраны труда, разрабатываются программы в области охраны труда, мероприятия по улучшению состояния охраны труда.

Третий этап включает в себя создание документированных процедур, внедрение, оценку эффективности проведенных мероприятий. В рамках третьего этапа авторы предлагают разработать комплекс стандартов, в частности: «Проверка и мониторинг СУОТ», «Разработка и утверждение документации», «Готовность к аварийным ситуациям и ответное реагирование».

Четвертый этап состоит в аудите внедренной СУОТ [7].

Основная направленность работ автора О. В. Кузьминой - изучение подготовительных работ к процессу внедрения СУОТ [8]. О. В. Кузьмина отмечает, что до процесса внедрения СУОТ следует 
идентифицировать опасности по подразделениям и сформировать общий перечень опасностей и произвести оценки профессиональных рисков предприятия. Интересно, что идентификацию опасностей автор выводит из основных элементов внедрения СУОТ и делает ее необходимой предварительной процедурой.

Автор делает акцент на то, что изначально следует организовать обучение работников на курсах повышения квалификации целевого назначения по внедрению и функционированию СУОТ.

Необходимость повышения квалификации, задействованного во внедрении персонала, отмечают также авторы А. А. Кулешов и Н. Г. Николаева [7]. Ими, при внедрении СУОТ в систему управления строительной организации, был разработан курс лекций и методических материалов, подробно отражающих все изменения в деятельности организации и проводилось обучение персонала.

Авторами Шабановой Д. Н., Александровой А. В. и др. рассмотрены современные нормативно-правовые основы и стандарты в области управления охраной труда в организации. Раскрыты аспекты внедрения системы охраны здоровья и безопасности труда с учетом требований проекта международного стандарта ISO/DIS 45001 «Системы менеджмента охраны здоровья и безопасности труда - Требования и рекомендации по применению». В работе систематизированы процедуры внедрения и стандартизации в области создания и функционирования СУОТ на предприятиях, через призму ключевых обязанностей работодателя по обеспечению безопасных условий и охраны труда. [9].

Таким образом, внедрение системы управления охраной труда на предприятиях должно происходить с учетом действующих нормативных документов и разработанной документации по управлению безопасности и охраны труда, которая должна иметь методическую направленность.

Путем выработки правил, разработки нормативной документации и положений, описывающих порядок создания, внедрения и поддержания эффективного функционирования СУОТ на основе стандартов достигается профессионализм, компетенции и контролируемое, предсказуемое поведение персонала, участвующего в производственной деятельности или оказании услуг.

Создание систем управления охраной труда на предприятиях и в организациях способствует совершенствованию работы по охране труда, ведет к сокращению производственного травматизма и профессиональной заболеваемости, а внедрение системы управления охраной труда, апробированной международной практикой, позволит усовершенствовать управление охраной труда в организациях республики. Наличие единой модели системы управления охраной труда позволяет устанавливать соответствие действий работодателя по охране труда нормативным требованиям охраны труда и безопасности производства.

Таким образом, система управления охраной труда предприятия должна охватывать все стороны производственно-хозяйственной деятельности предприятия, быть методической основой современного управления охраной труда и основой решения вопросов обеспечения безопасности и охраны труда в производственных условиях.

Исходя из вышеизложенного, процесс внедрения на предприятиях СУОТ должен быть систематизирован и поделен на несколько этапов, каждый из которых должен иметь свои задачи. Это подтверждается опытом внедрение системы управления охраной труда, апробированным международной практикой.

В делении методики внедрения на определенные этапы следует, на наш взгляд, учесть исследования ученых А. Ахметова и У. Ибатуллина, которые в своих работах предлагают алгоритмы подготовки и внедрения системы управления охраной труда на предприятии, с делением процесса внедрения на три этапа: предварительный, подготовительный и основной.

Применение, при разработке Методики внедрения СУОТ, данного подхода позволит эффективно определять порядок и сроки реализации мероприятий по внедрению СУОТ.

Кроме того, авторами А. А. Кулешовым и Н. Г. Николаевой, О. В. Кузьминой, Е. В. Юркинской, отмеченная важность повышения квалификации персонала до начала внедрения СУОТ в организации, что подтверждает актуальность разработки учебной программы по повышению квалификации «Внедрение интегрированной системы управления охраной труда на основе управления профессиональными рисками на предприятии». 


\author{
Mukanova Dinara Bazarovna \\ Senior Research Fellow, Laboratory for Research on Working Conditions \\ «Republican Research Institute for Labor Protection, \\ Ministry of Labor and Social Protection of the Population \\ of the Republic of Kazakhstan», Nur-Sultan, Kazakhstan. \\ Master of Science, economics \\ E-mail: nauka@rniiot.kz \\ ORCID ID: 0000-0002-1744-6151
}

\title{
Review of sources on the development and implementation of occupational safety management systems
}

\begin{abstract}
The article presents an analysis of approaches to the implementation of the occupational safety management system. The authors of the analyzed works propose to divide the implementation into two, three or four stages, but in one the authors ' opinion coincides. The whole process of implementation should be divided into successive stages. The presence of a single model of the occupational safety management system allows to establish compliance of the employer's actions on occupational safety with the regulatory requirements of occupational safety and production safety. The implementation process at enterprises, the labor protection management system should be systematized and divided into several stages, each of which should have its own tasks. This is confirmed by the experience of the implementation of the occupational safety management system, tested by international practice and is quite successfully applied by enterprises in practice.
\end{abstract}

Keywords: implementation, algorithm, stages, labor protection management system, safety.

Ссылка на данную статью: Муканова Д. (2019) Обзор источников по вопросу разработки и внедрения системы управления охраной труда. Материалы Международной практической интернет-конференции «Актуальные проблемы науки» / Materials of International Practical Internet Conference "Challenges of Science". ISBN 978-601-323-144-0. Выпуск II, ноябрь 2019. С.: 72 - 75. https://doi.org/10.31643/2019.013

\section{Список использованных источников}

[1] Пушилин Н.К., Трубицын И.В., Малек И.М. Рекомендации по внедрению системы управления охраной труда в колхозах, совхозах и других сельскохозяйственных предприятиях. [Текст] // Воронежской область, 1986г. -С 1112. https://www.dissercat.com/content/issledovaniya-razrabotka-i-vnedrenie-sistemy-upravleniya-okhranoi-truda

[2] Государственный агропромышленный комитет СССР. Всесоюзный научно-исследовательский институт охранный труда. Общие положения и методические указания по управлению охраной труда в системы Госагропрома СССР/ Москава-1988. https://dnaop.com/html/43614/doc-\%D0\%94\%D0\%9D\%D0\%90\%D0\%9E\%D0\%9F_2.0.00-4.02-88

[3] Трухачев, Борис Филиппович. Исследования, разработка и внедрение системы управления охраной труда. [Текст] //.Дис. . канд. экон. наук: 08.00.05: Воронеж, 2010, 58 с. ил. РГБ ОД, 61 10-5/1816. https://www.dissercat.com/content/issledovaniya-razrabotka-i-vnedrenie-sistemy-upravleniya-okhranoi-truda

[4] Ахметов А., Ибатуллин У., Общий алгоритм. Подготовка и внедрение системы управления охраной труда в организации в соответствии с ГОСТ Р 12.0.007-2009. [Электронный ресурс]/ Безопасность и охрана труда. -2011. №3. -C. 4-8. https://biota.ru/publishing/magazine/bezopasnost-i-oxrana-truda-\%E2\%84\%963-2011/obshhij-algoritm.podgotovka-i-vnedrenie-sistemyi-upravleniya-oxranoj-truda.html

[5] Юркинская Е.В. Формирование интегрированной системы менеджмента качества на предприятии. [Текст] // диссертация ... кандидата экономических наук: 08.00.05: РГБ ОД, ил.61 04-8/226. Санкт-Петербург, 2003. - 185 с. https://www.dissercat.com/content/formirovanie-integrirovannoi-sistemy-menedzhmenta-kachestva-na-predpriyatii

[6] Дмитриева. Ю.В. Повышение эффективности управления охраны труда на предприятиях. [Текст] // Москва, 2010г. -C.121-126. http://www.dslib.net/oxr-truda/povyshenie-jeffektivnosti-upravlenija-ohranoj-truda-na-predprijatijahmashinostroenija.html

[7] Кулешов А.А., Николаева Н.Г., Внедрение системы управления охраной труда на примере организации ООО «Ак таш». [Текст] // Казань, 2014, -C. 241-243. https://cyberleninka.ru/article/v/vnedrenie-sistemy-upravleniya-ohranoytruda-na-primere-organizatsii-ooo-ak-tash

[8] Кузьмина О.В., Оценка результатов внедрения и адаптации системы менеджмента безопасности труда и охраны здоровья на «АО Красмаш» [Текст] // Красноярск, 2016. -С. 500-501). https://cyberleninka.ru/article/v/aktualnostvnedreniya-sistemy-menedzhmenta-bezopasnosti-truda-i-ohrany-zdorovya-v-ao-krasmash

[9] Шабанова Д.Н., Александрова А.В. Аспекты нормативно-правового регулирования и стандартизации в построении системы управления охраной труда в организациях. [Электронный ресурс] / Политематический сетевой электронный научный журнал Кубанского государственного аграрного университета. 2017. № 131. С. 515-527. https://cyberleninka.ru/article/v/aspekty-normativno-pravovogo-regulirovaniya-i-standartizatsii-v-postroenii-sistemyupravleniya-ohranoy-truda-v-organizatsiyah 